\title{
-2518A/G polymorphism of monocyte chemotactic protein 1 (MCP-1/CCL2) is associated with cutaneous mastocytosis
}

\author{
Hanna Ługowska-Umer ${ }^{1}$, Monika Zabłotna ${ }^{1}$, Magdalena Lange ${ }^{1}$, Marek Niedoszytko², Roman J. Nowicki ${ }^{1}$, \\ Bogusław Nedoszytko ${ }^{1}$
}

${ }^{1}$ Department of Dermatology, Venereology and Allergology, Medical University of Gdansk, Gdansk, Poland

${ }^{2}$ Department of Allergology, Medical University of Gdansk, Gdansk, Poland

\author{
Adv Dermatol Allergol 2021; XXXVIII (6): 1039-1043
}

DOI: https://doi.org/10.5114/ada.2021.112277

\begin{abstract}
Introduction: Mastocytosis is a rare heterogeneous disease associated with pathological accumulation of mast cells (MCs) in one or more organs. The disease may be limited to the skin (cutaneous mastocytosis - CM), or present an internal organ involvement (systemic mastocytosis - SM). Pathophysiology of the disease is not well established. However altered proliferation, differentiation and chemotaxis of $M C$ may play an essential role in the development of the disease. The monocyte chemotactic protein 1 (MCP-1/CCL2) may be one of the factors responsible for MCS migration to the skin and other organs.

Aim: To analyse the frequency of biallelic A/G polymorphisms at position -2518 in the promoter of the MCP-1 gene and compare the serum level of MCP-1 in patients with both forms of mastocytosis and the healthy control group. Material and methods: Using ARMS-PCR methods we analysed -2518A/G polymorphisms in the promoter region of the MCP-1 gene in 127 mastocytosis patients ( 95 CM and 32 SM), and 160 healthy controls. Additionally, the MCP-1 serum level was detected with ELISA technique in 70 patients and 40 controls.

Results: We have found that CM patients have more frequently the GG genotype of the MCP-1 gene $(p=0.01)$ in comparison to SM patients and controls. The GG genotype was more frequent in children than in adults $(p=0.02)$. The MCP-1 serum level was higher in SM patients than in CM patients and controls.

Conclusions: Results of this study indicate that cutaneous mastocytosis could be associated with the $-2518 \mathrm{~A} / \mathrm{G}$ MPC-1 gene polymorphism.
\end{abstract}

Key words: MCP-1 gene polymorphism, systemic mastocytosis, cutaneous mastocytosis.

\section{Introduction}

Mastocytosis is considered a disease of bone marrow origin, characterized by the clonal growth and subsequent accumulation of the mast cells (MCs) in the tissues.

WHO classification of mastocytosis includes: cutaneous mastocytosis (CM), where the MCs infiltration is limited to the skin, and systemic mastocytosis (SM), characterized by the accumulation of the MCs in bone marrow and internal organs. SM varies from clinically indolent to aggressive forms. The third and most uncommon clinical form is extracutaneous mast cell neoplasm, either malignant or benign [1].
The diagnosis of CM is based on the histopathological examination of the skin and clinical features like positive Darier sign.

The SM diagnosis requires the presence of the major WHO criterion ( $\geq 15$ MCs in aggregates in bone marrow and/or other extracutaneous organ(s)) and one from four minor criteria (1) the presence of atypical MCs in lesional tissues, 2) the presence of the point mutation in codon 816 in KIT in bone marrow, peripheral blood, or any extracutaneous organ, 3) the aberrant expression of CD2 and/or CD25 by neoplastic MCs, 4) a persistently elevated (> $20 \mathrm{ng} / \mathrm{ml}$ ) tryptase serum level) [2].

Point mutations in the KIT gene (transmembrane tyrosine kinase receptor) plays the key role in pathogenesis

Address for correspondence: Hanna Ługowska-Umer, Department of Dermatology, Venereology and Allergology, Medical University of Gdansk, Gdansk, Poland, phone: +48 501681 127, e-mail: hannaumer@gumed.edu.pl Received: 19.07.2020, accepted: 27.07.2020. 
of the disease [3]. But not only the KIT mutations are responsible for growth of mast cells. The new data suggest the involvement of cytokines and chemokines like interleukin (IL) 4 (IL-4), IL-6, IL-10, IL-13 and IL-31 in pathogenesis of mastocytosis [4-6]. One of the objects of interest in the pathogenesis of mastocytosis is the mechanism behind the pathological inflow of the MCs to the tissues.

MCs derive from the bone marrow progenitor cell and migrate to the tissues where they mature under the influence of local microenvironmental conditions [7, 8]. In physiological conditions MCs play a crucial role in innate and acquired immunity, defence against infections, but also effect on angiogenesis, proliferation, epithelium remodelling, and cancer development mechanisms $[9,10]$.

After activation by diverse stimuli MCs release mediators: histamine, proteases, and the plethora of cytokines like: GM-CSF, TNF- $\alpha$, IL-1, IL-3, IL-5 and chemokines: eotaxin, IL-8, RANTES, MCP-1. Those molecules play an important role in the pathogenesis of many allergic and inflammatory diseases $[9,11]$. It has been found that MCs are recruited in the inflammatory site by MCP-1 [12]. Moreover, mast cells in vitro release significant amounts of preformed MCP-1 after stimulation with biological proinflammatory stimuli (anti-lgE) [13].

The MCP-1/CCL-2 (monocyte chemoattractant protein-1) is a -chemokine member of the C-C chemokine family and is found as a potent chemotactic factor capable of attracting the inflammatory cells like lymphocytes, macrophages and basophilic cells [13]. Also mast cells can be recruited to the inflammatory site by MCP-1 and secrete proinflammatory mediators including histamine, heparin, VEGF and IL-8 [13]. MCP-1 mediates its effect through the receptor CCR2 expressed on the MC [13].

The MCP-1 due to its emerging role in mediating the inflammation by recruitment of inflammatory cells into tissue, may become a target for diagnostic and therapeutic intervention and that is why it became one of the most studied chemokine recently. There are data confirming that the polymorphism in the distal regulatory region of the $M C P-1$ gene, at $-2518 \mathrm{~A} / \mathrm{G}$ position, affect $M C P-1$ transcriptional activity in response to inflammatory stimuli [14].

The association between polymorphic variants of MCP-1 and pathogenesis of some inflammatory diseases like rheumatoid arthritis [15], diabetes mellitus [16], and multiple sclerosis [17] has been confirmed.

Genetic variations of MCP-1 have been reported to influence the serum level of MCP-1 and the incidence of myocardial infarction [18].

The involvement of MCP-1 in pathogenesis of mastocytosis was confirmed by Greiner et al. [19]. The authors identified MPC-1 as a KIT D816V-induced cytokine. Moreover patients with SM presented high serum levels of CCL-2, and they correlated with poor survival outcome [19].
To our knowledge, there were no studies presenting association of the MCP-1 polymorphism and mastocytosis.

\section{Aim}

The aim of our study is to analyse the frequency of biallelic A/G polymorphism at position -2518 in the promoter region of the $M C P-1$ gene and the concentration of MCP-1 in the blood of SM, CM and control groups.

\section{Material and methods}

Two groups of patients were examined. In the first group, the $-2518 \mathrm{~A} / \mathrm{G}$ polymorphism was detected. This group consisted of 127 patients with mastocytosis, $95 \mathrm{di}$ agnosed as CM (65 children, 30 adults) and 32 diagnosed as SM (31 adults, 1 child).

In the second study group, in which the MCP-1 serum level was evaluated, 70 patients and 40 controls were included.

Diagnosis of systemic mastocytosis was based on WHO criteria [2], and CM diagnosis was based on the clinical examination and histopathological result. The control group consisted of 160 patients. All subjects were of Eastern European/Polish descent, and they were exclusively the patients of the Department of Dermatology, Venereology and Allergology and the Department of Allergy and Pneumonology of the Medical University of Gdansk.

The study was approved by the local research ethics committee of the Medical University of Gdansk, Poland.

\section{MCP-1 genotyping}

The $-2518 \mathrm{~A} / \mathrm{G}$ polymorphism was detected using the amplification refractory mutation system polymerase chain reaction method (ARMS-PCR) [20].

\section{MCP-1 serum levels}

The serum concentration of MCP-1 was detected using the ELISA technique in 70 patients and 40 controls (Human ELISA kit, Diaclone SAS, France).

\section{Statistical analysis}

$\chi^{2}$ analysis was employed to test the significance of differences in the observed alleles and genotypes between groups. A logistic regression model was used to calculate the odds ratios (ORs) and the 95\% confidence intervals (Cls). The Mann-Whitney U-test was used to compare the median values, and the correlation was determined using mean Spearman coefficient values. Analyses were performed with the Statistica 12.0 software package (StatSoft, Inc., 2015). P-value < 0.05 was considered statistically significant. 


\section{Results}

\section{MCP-1 polymorphisms}

We have not found any statistically significant differences between the groups of patients with mastocytosis and the control group (Table 1). But the MCP-1 -2518 GG genotype was more frequent in the children group of patients with mastocytosis comparing to the adult patients with mastocytosis ( $24.24 \%$ vs. $4.92 \%, p=0.002$; OR $=$ $6.19,95 \% \mathrm{Cl}: 1.70-22.47, p=0.006)$, and also comparing with the control group (24.24\% vs. $10.63 \%, p=0.008$; OR $=2.69,95 \% \mathrm{Cl}: 1.26-5.73, p=0.01)$.

Moreover, the GG phenotype was more common in subjects with CM comparing to SM patients $(18.95 \%$ vs. $3.13 \%, p=0.029 ; \mathrm{OR}=7.25,95 \% \mathrm{Cl}: 0.93-56.65$, $p=0.05)$.

In the group of children with CM, the - 2518 GG genotype was more frequent in children with a less severe form of the disease (area of skin involvement up to 49\%) (25.53\% vs. $14.29 \%, p=0.008)$.

\section{MCP-1 serum level}

The MCP-1 serum concentration was higher in the group of patients with mastocytosis comparing to healthy controls (median: 353.6; range: 149.2-664.0 vs. median: 303.0; range: 130.4-544.4; $p=0.03$ ) (Figure 1).

In group of an adults the MCP-1 concentration was higher in adult group of the patients with mastocytosis comparing to children group of pateints with mastocytosis (median: 369.4; range: $149.2-622.6$ vs. median: 344.0; range: $165.2-664.0 ; p=0.037$ ), and also statistically significantly higher comparing to healthy controls (median: 369.4; range: 149.2-622.6 vs. median: 303.0; range: $130.4-544.4 ; p=0.003)$. The MCP-1 concentration was also higher in SM patients (almost all adults) vs. controls $(p<0.015)$.

\section{Discussion}

The mechanism of migration of the clonal MCs to the skin and other organs is still not fully understood.

MCP-1 is thought to be one of the most potent chemokines, which may influence the recruitment of the MCs into the tissue [13]. To our knowledge, the association between the genetic polymorphism of $-2518 \mathrm{~A} / \mathrm{G}$ MCP-1 and pathogenesis of mastocytosis has never been published. The association of polymorphic variants of MCP-1 and pathogenesis of systemic lupus erythematous in Mexican patients has been proved [21], moreover Tucci et al. established that $\mathrm{GG}$ and $\mathrm{A} / \mathrm{G}$ genotypes were more frequent in SLE patients comparing to the control group [18]. The functional promoter polymorphism of MCP-1 was chosen due to the established effect on chemokine expression [22].

Our study demonstrated the association of the -2518 A/G polymorphism and cutaneous form of mastocytosis. We revealed that the GG phenotype was more common in subjects with CM comparing to SM patients $(p=0.002)$, and more frequent in children, especially with a benign form of the disease. In the group of children with mastocytosis, there was only one child with SM and his genotype was AG. Those data may suggest that the GG phenotype may have a "protective" effect on the development and severity of mastocytosis.

Those findings might be explained by the fact that the receptor for MCP-1 CCR2 presents both pro-inflammatory and anti-inflammatory functions [13]. The proinflammatory role is mediated through the receptors located on APCs and T-cells, and the anti-inflammatory function of CCR2 is dependent on CCR2 expression in regulatory T-cells [13]. MCP-1 is an attractant for eosinophils, monocytes, mast cells and basophils, and can also drive Th-lymphocytes towards IL-4 - producing Th2 cells [23]. In Th2-mediated diseases, like asthma, the CCL2 level is increased and its neutralization in animal mod-

Table 1. Frequencies of genotypes and alleles for MCP-1 -2581 A/G in patients with mastocytosis and control subjects

\begin{tabular}{|c|c|c|c|c|c|c|c|}
\hline $\begin{array}{l}\text { Genotypes and alleles } \\
\text { MCP- } 1-2581 \text { A/G }\end{array}$ & $\begin{array}{l}\text { Controls } \\
n=160\end{array}$ & $\begin{array}{l}\text { Mastocytosis patients } \\
\qquad n=127\end{array}$ & $P$-value & $\begin{array}{c}\text { CM patients } \\
\quad n=95\end{array}$ & $\begin{array}{l}\text { SM patients } \\
n=32\end{array}$ & $P$-value & $\begin{array}{l}\text { OR }(\mathrm{Cl}) \\
P \text {-value }\end{array}$ \\
\hline AA & $\begin{array}{c}85 \\
53.13 \%\end{array}$ & $\begin{array}{c}66 \\
51.97 \%\end{array}$ & NS & $\begin{array}{c}48 \\
50.53 \%\end{array}$ & $\begin{array}{c}18 \\
56.25 \%\end{array}$ & NS & NS \\
\hline$A G$ & $\begin{array}{c}58 \\
36.25 \%\end{array}$ & $\begin{array}{c}42 \\
33.07 \%\end{array}$ & NS & $\begin{array}{c}29 \\
30.52 \%\end{array}$ & $\begin{array}{c}13 \\
40.62 \%\end{array}$ & NS & NS \\
\hline GG & $\begin{array}{c}17 \\
10.62 \%\end{array}$ & $\begin{array}{c}19 \\
14.96 \%\end{array}$ & NS & $\begin{array}{c}18 \\
18.95 \%\end{array}$ & $\begin{array}{c}1 \\
3.13 \%\end{array}$ & 0.03 & $\begin{array}{c}7.25 \\
(0.93-56.65) \\
0.05\end{array}$ \\
\hline & $n=320$ & $n=254$ & & $n=190$ & $n=64$ & & \\
\hline A & $\begin{array}{c}228 \\
71.25 \%\end{array}$ & $\begin{array}{c}174 \\
68.50 \%\end{array}$ & NS & $\begin{array}{c}125 \\
65.79 \%\end{array}$ & $\begin{array}{c}49 \\
76.56 \%\end{array}$ & NS & NS \\
\hline G & $\begin{array}{c}92 \\
28.75 \%\end{array}$ & $\begin{array}{c}80 \\
31.50 \%\end{array}$ & & $\begin{array}{c}65 \\
34.21 \%\end{array}$ & $\begin{array}{c}15 \\
23.44 \%\end{array}$ & & \\
\hline
\end{tabular}

OR - odds ratio, Cl - confidence interval, NS - not significant. 


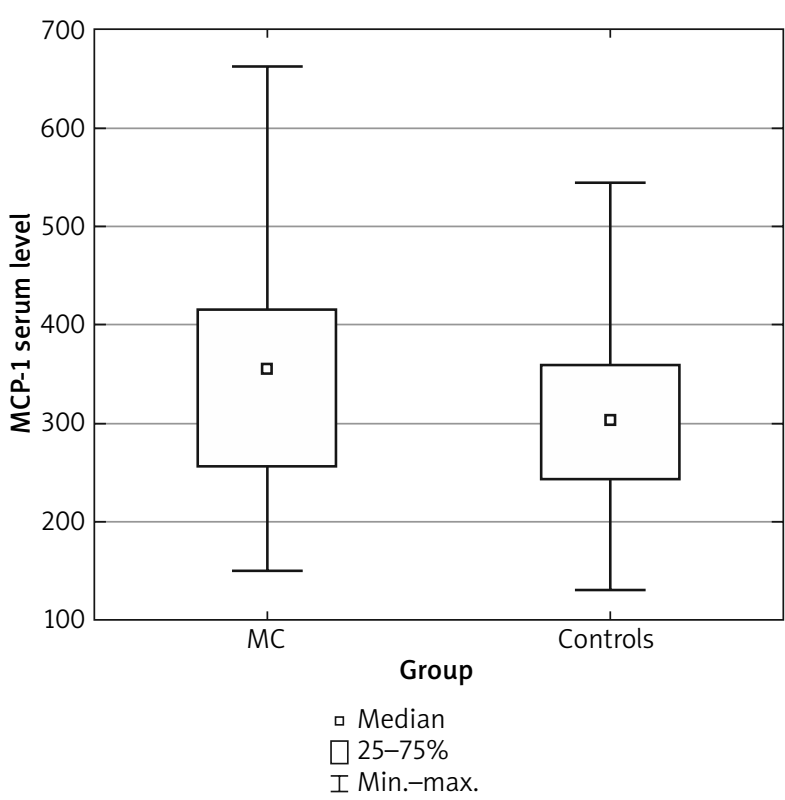

Figure 1. Serum level of MCP-1 in group of patients with mastocytosis (MC) and control group (controls)

els ameliorates the disease [24]. Based on those data, Czech authors were studying the role of MCP-1 in asthma and allergy [25], but they failed to prove any association between any of the investigated polymorphisms in the MCP-1 and CCR2 genes and the clinical manifestation of allergic diseases [25].

Moreover, CCL2 levels were confirmed to be higher in rheumatoid arthritis [26], insulin resistant diabetes mellitus [27], inflammatory bowel diseases [28] and finally the MCP-1 concentration was also elevated in ischemia related neuronal death [29, 30].

Our data are in line with the experiments of Greiner et al. [19]. Similarly, in SM patients we observed the elevated serum level of MCP-1. To our knowledge, we are the first who demonstrated that the MCP-1 -2518 GG genotype was more frequent in the children group of patients with mastocytosis comparing to the adult patients with mastocytosis.

The MCP-1 level is higher in adults than in children and in SM patients than in controls suggesting an association with disease progression. Examination of the MCP-1 expression in different tissues will be needed to confirm the role of this chemokine in mastocytosis.

To define the role of chemokines in the pathogenesis of diseases is still a challenge, especially because usually they are a part of the "cascade", where the final effect is dependent on multiple co-factors.

\section{Conclusions}

We found the association of the -2518 A/G polymorphism and cutaneous form of mastocytosis. The GG phe- notype may have a "protective" effect on the development and severity of mastocytosis.

The inhibition of this chemokine may present a therapeutic option or may be useful for predicting the course of the disease [9]. We also obtain the hypothesis that examination of genetic polymorphisms of the -2518 MCP-1 gene might become a predicting factor for the clinical course of the disease. We are aware that this is only a pilot study and further examinations should be performed to establish that hypothesis.

\section{Acknowledgments}

The study was supported by the Polish Ministry of Science and Higher Education - grant 02-0066/07/253.

\section{Conflict of interest}

The authors declare na conflict of interest.

\section{References}

1. Horny HP, Sotlar K, Valent P. Mastocytosis: state of the art. Pathobiology 2007; 74: 121-32.

2. Valent P, Horny HP, Li CY. Mastocytosis (mast cell disease). World Health Organization classification of tumours: pathology and genetics. In: Tumours of Haematopoietic and Lymphoid Tissues. Jaffe ES, Harris NL, Stein H, Vardiman JW (eds). WHO, Geneva 2001; 1: 291-302.

3. Valent P, Horny HP, Escribano L, et al. Diagnostic criteria and classification of mastocytosis: a consensus proposal. Leuk Res 2001; 25: 603-25.

4. Nedoszytko B, Niedoszytko M, Lange M, et al. Interleukin-13 promoter gene polymorphism $-1112 \mathrm{C} / \mathrm{T}$ is associated with the systemic form of mastocytosis. Allergy 2009; 64: 287-94.

5. Rausz E, Szilagyi A, Nedoszytko B, et al. Comparative analysis of IL6 and IL6 receptor gene polymorphisms in mastocytosis. Br J Haematol 2013; 160: 216-9.

6. Lange M, Glen J, Zablotna M, et al. Interleukin-31 Polymorphisms and serum IL-31 level in patients with mastocytosis: correlation with clinical presentation and pruritus. Acta Derm Venereol 2017; 97: 47-53.

7. Metcalfe DD. Mast cells and mastocytosis. Blood 2008; 112: 946-56.

8. Kitamura Y, Ito A. Mast cell-committed progenitors. Proc Natl Acad Sci USA 2005; 102: 11129-30.

9. Castellani ML, De Lutiis DA, Toniato E, et al. Impact of RANTES, MCP-1 and IL-8 in mast cells. J Biol Regul Homeost Agents 2010; 24: 1-6.

10. Theoharides TC, Conti P. Mast cells: the Jekyll and Hyde of tumor growth. Trends Immunol 2004; 25: 235-41.

11. Ozdemir C, Akdis M, Akdis CA. T-cell response to allergens. Chem Immunol Allergy 2010; 95: 22-4.

12. Conti P, Pang X, Boucher W, et al. Impact of Rantes and MCP-1 chemokines on in vivo basophilic cell recruitment in rat skin injection model and their role in modyifying the protein and mRNA levels for histidine decarboxylase. Blood 1997; 89: 4120-7.

13. Conti P. Role of TNF alpha, IL-33 and CCL2/MCP-1 on mast cell activity. Glob I Immunol Allerg Dis 2013; 1: 35-42.

14. Martin ES, Schneeberg EE, Frederico MA, et al. The -2518 A/G polymorphism in the monocyte chemoattractant protein 1 
gene (MCP-1) is associated with an increased risk of rheumatoid arthritis in Argentine patients. Clin Rheumatol 2016; 35: 3057-61.

15. Hayashida K, Nanki T, Girschick H, et al. Synovial stromal cells from rheumatoid arthritis patients attract monocytes by producing MCP-1 and IL-8. Arthritis Res 2001; 3: 118-26.

16. Sartipy P, Loskutoff DJ. Monocyte chemoattractant protein 1 in obesity and insulin resistance. Proc Natl Acad Sci USA 2003; 100: 7265-70.

17. Sorensen TL, Ransohoff RM, Strieter RM, et al. Chemokine CCL2 and chemokine receptor CCR2 in early active multiple sclerosis. Eur J Neurol 2004; 11: 445-9.

18. Tucci M, Barnes EV, Sobel ES, et al. Strong association of a functional polymorphism in the monocyte chemoattractant protein 1 promoter gene with lupus nephritis. Arthritis Rheum 2004; 50: 1842-9.

19. Greiner G, Witzeneder N, Berger A, et al. CCl2 is a Kt D816Vdependent modulator of the bone marrow microenvironment in systemic mastocytosis. Blood 2017; 129: 371-82.

20. Naderi M, Hashemi M, Karami H, et al. Lack of association between rs1024611 (-2581 A/G) polymorphism in CC-chemokine ligand 2 and susceptibility to pulmonary tuberculosis in Zahedan. Southeast Iran Prague Med Rep 2011; 112: 272-8.

21. Lima G, Soto-Vega E, Atisha-Fregoso Y, et al. MCP-1, RANTES, and SDF-1 polymorphisms in Mexican patients with systemic lupus erythematosus. Hum Immunol 2007; 68: 980-5.

22. Wang L, Yang L, Gao L, et al. A functional promoter polymorphism in monocyte chemaoattractant protein-1 is associated with psoriasis. Int J Immunogenet 2008; 35: 45-9.

23. Karpus WJ, Lukacs NW, Kennedy KJ, et al. Differential CC chemokine-induced enhancement of T helper cell cytokine production. I Immunol 1997; 158: 4129-36.

24. Gonzalo JA, Lloyd CM, Wen D, et al. The coordinated action of CC chemokines in the lung orchestrates allergic allergic inflammation and airway hyper 1-responsiveness. J Exp Med 1998; 188: 157-67.

25. Izakovicova Holla L, Mrazekt F, Petrekt M. MCP-1 and CCR2 gene polymorphism $\mathrm{s}$ in Czech patients with allergic disorders. Int J Immunogent 2009; 36: 69-72.

26. Rantapaa-Dahlqvist S, Boman K, Tarkowski A, et al. Up regulation of monocyte chemoattractant protein-1 expression in anti-citrulline antibody and immunoglobulin $\mathrm{M}$ rheumatoid factor positive subjects precedes onset of inflammatory response and development of overt rheumatoid arthritis. Ann Rheum Dis 2007; 66: 121-3.

27. Kamei N, Tobe K, Suzuki R, et al. Overexpression of monocyte chemoattractant protein-1 in adipose tissues causes macrophage recruitment and insulin resistance. J Biol Chem 2006; 281: 26602-14.

28. Spoettl T, Hausmann M, Herlyn M, et al. Monocyte chemoattractant protein-1 (MCP-1) inhibits the intestinal-like differentiation of monocytes. Clin Exp Immunol 2006; 145: 190-9.

29. Sakurai-Yamashita Y, Shigematsu K, Yamashita K, et al. Expression of MCP-1 in the hippocampus of SHRSP with ischemia-related delayed neuronal death. Cell Mol Neurobiol 2006; 26: 823-31.

30. Deshmane SL, Kremlev S, Amini S, et al. Monocyte chemoattractant protein-1 (MCP-1): an overview. J Interferon Cytokin Res 2009; 29: 313-26. 